\title{
TINGKAT KEMATANGAN BEHAVIOR BASED SAFETY (BBS) PADA PROGRAM PEKA (PENGAMATAN KESELAMATAN KERJA) DI PT X
}

\author{
BEHAVIOR BASED SAFETY (BBS) MATURITY LEVEL IN SAFETY OBSERVATIONS \\ PROGRAM AT PT X
}

Mahega Awalatul Aini

Departemen Keselamatan dan Kesehatan Kerja

Fakultas Kesehatan Masyarakat Universitas Airlangga

E-mail: mahe.awalatulaini@yahoo.co.id

\begin{abstract}
The number of accidents at work increase based on data from ILO (International Labor Organization). That accidents are most caused by unsafe behavior. Based on some researches about more than $80 \%$ accidents are caused by unsafe action, and the rest are caused by unsafe condition. Behavior Based Safety (BBS) is a approach in order to creates safe behavior and to decreases the number of accidents. The aimed of this research is analyzing the maturity level of BBS from PEKA program in PT X.

This research used observational method with a cross sectional approach, and descriptive analysis. Interviews were conducted to 4 safety officers as respondents. This research used total sampling. The interviews were carried out to get more detailed information about every matrix in behavior safety maturity matrix. Every matrix were assessed their maturity level based on behavioral safety maturity ladder.

The results showed that maturity level of PEKA program was in level 2 (developing), level 3 (performing), and level 4 (high performing). But generally, the maturity level of PEKA program was in level 3 (performing).

Based on this results, it can be concluded that PEKA program was not in the same level. So, the recommendation for the company is to improve the implementation process of BBS in PEKA program.
\end{abstract}

Keywords: maturity, level, behavior 


\section{ABSTRAK}

Angka kecelakaan kerja cenderung meningkat berdasarkan data dari ILO (International Labor Organization). Penyebab utama dari kecelakaan tersebut adalah perilaku tidak aman. Berdasarkan beberapa penelitian, sekitar lebih dari 80\% kecelakaan disebabkan oleh perilaku tidak aman, dan sisanya disebabkan oleh kondisi tidak aman. Behavior Based Safety (BBS) adalah pendekatan yang dapat menciptakan perilaku aman dan dapat menurunkan angka kcelakaan . Penelitian ini dilakukan untuk menganalisis tingkat kematangan BBS dalam program PEKA di PT X.

Penelitian ini merupakan penelitian observasional dengan menggunakan pendekatan cross sectional, dan menggunakan analisis deskriptif. Wawancara dilakukan kepada 4 orang safety officer. Penelitian ini menggunakan teknik sampling yaitu total sampling. Wawancara dilakukan untuk mendapatkan informasi yang lebih mendalam mengenai setiap acuan dalam behavior safety maturity matrix. Kemudian setiap acuan dinilai tingkat kematangannya berdasarkan behavioral safety maturity ladder.

Hasil penelitian menunjukkan bahwa tingkat kematangan program PEKA berada pada PEKA di PT X berada pada level 2 (developing), level 3 (performing), dan level 4 (high performing). Namun secara umum, tingkat kematangan program PEKA berada pada level 3 (performing).

Berdasarkan hasil tersebut, maka dapat disimpulkan bahwa setiap acuan pada program PEKA tidak berada pada level yang sama. Maka, disarankan agar perusahaan memperbaiki proses pelaksanaan BBS dalam program PEKA.

\section{Kata kunci: kematangan, perilaku, acuan}

\section{PENDAHULUAN}

Tenaga kerja dalam melakukan pekerjaanya tentunya berinteraksi dengan berbagai potensi bahaya yang tidak jarang potensi bahaya tersebut dapat mengakibatkan kecelakaan di tempat kerja. ILO mencatat bahwa pada tahun 2013 terdapat 1 pekerja di dunia yang meninggal setiap 15 detik dan 160 pekerja sakit akibat pekerjaan.

Sedangkan berdasarkan data yang didapat dari website www.depkes.go.id milik Kementerian Kesehatan Republik Indonesia (2014) menyatakan bahwa kecelakaan akibat kerja yang terjadi dari tahun 2011 - 2014 dapat dilihat pada tabel di bawah ini:

Tabel 1. Data Kasus Kecelakaan Akibat Kerja (KAK) di Indonesia Tahun 2011-2014

\begin{tabular}{|c|c|}
\hline Tahun & $\begin{array}{c}\text { Kasus Kecelakaan } \\
\text { Akibat Kerja }\end{array}$ \\
\hline 2011 & 9891 \\
\hline 2012 & 21735 \\
\hline 2013 & 35917 \\
\hline 2014 & 24910 \\
\hline
\end{tabular}

Sumber: Data Kasus Kecelakaan Akibat Kerja di Indonesia Tahun 2011 - 2014 (www.depkes.go.id, 2014)
Dari Tabel 1. di atas didapatkan bahwa terjadi peningkatan angka KAK setiap tahunnya, apalagi pada tahun 2013 yang mencapai angka 35917 kasus. Hal ini selaras dengan data dari ILO sebelumnya. Hal ini membuktikan bahwa kasus kecelakaan kerja menunjukkan angka yang sangat besar pada tahun 2013 baik di Indonesia maupun di dunia.

Secara umum terdapat 2 hal yang meyebabkan kecelakaan kerja, yaitu perilaku tidak aman (unsafe action) dan kondisi tidak aman (unsafe condition). National Safety Council (NSC) (2011) melakukan riset dan menyatakan bahwa $88 \%$ penyebab kecelakaan kerja adalah perilaku tidak aman, 10\% penyebabnya adalah kondisi tidak aman, dan 2\% sisanya tidak diketahui pasti penyebabnya. Sedangkan penelitian lain juga menyatakan hal yang serupa yaitu, lebih dari $80 \%$ kecelakaan kerja disebabkan oleh faktor manusia (unsafe action) (Ismail, et.al, 2012).

Hal ini seharusnya menjadi perhatian bagi setiap industri, melihat fakta bahwa penyebab kecelakaan kerja terbesar adalah perilaku manusia, maka untuk menurunkan angka kecelakaan kerja yang terjadi, salah 
satu upaya yang dapat dilakukan adalah dengan memodifikasi perilaku tenaga kerja. Menurut Jasiulewicz, et.al (2015) saat ini terdapat alternatif baru untuk melakukan modifikasi perilaku tenaga kerja yaitu dengan penerapan konsep Behavior Based Safety (BBS).

Pendekatan ini terbukti mampu meningkatkan perilaku aman dan menurunkan angka kecelakaan kerja, salah satu contohnya adalah penelitian yang dilakukan oleh Yusnita Handayani (2011) mengenai Aktifasi Program BBS di PT. Denso Indonesia menyatakan bahwa BBS dapat menurunkan angka kecelakaan sebesar 66,67\% - 88,89\%. Bahkan menurut Cooper (2009) pendekatan berbasis perilaku dapat menurunkan angka kecelakaan hingga $59,6 \%$, dan ini merupakan prosentase penurunan angka kecelakaan paling besar jika dibandingkan dengan pendekatanpendekatan lainnya, seperti ergonomi, pengubahan teknis, penyelesaian masalah, dan lain-lain.

PT X sebagai salah satu Refinery Unit (RU) dari perusahaan energi nasional yang bergerak dalam sektor migas dengan tingkat risiko kecelakaan yang tinggi tentunya mempunyai beberapa program yang bertujuan untuk menurunkan angka kecelakaan kerja. Salah satunya adalah program dengan konsep Behavior Based Safety (BBS) yaitu program PEKA (Pengamatan Keselamatan Kerja).

Program PEKA merupakan program yang berbasis BBS yang diterapkan di PT X yang mulai dilaksanakan pada tahun 2009 . Program ini bertujuan untuk meningkatkan pengetahuan mengidentifikasi bahaya, mengkomunikasikan serta mengintervensi setiap individu sehingga akhirnya dapat mempunyai standard kerja yang lebih tinggi dengan harapan dapat menurunkan angka kecelakaan kerja secara signifikan.

Namun, didapat informasi bahwa berdasarkan data investigasi kecelakaan kerja PT X yang terjadi selama 4 tahun terakhir yaitu tahun 2012 - 2015, jumlah angka kecelakaan kerja di PT X dapat dilihat pada tabel di bawah ini:

Tabel 2. Angka Kecelakaan Kerja di PT X Tahun $2012-2015$

\begin{tabular}{|c|c|}
\hline Tahun & $\begin{array}{c}\text { Angka Kecelakaan } \\
\text { Kerja }\end{array}$ \\
\hline 2012 & 23 \\
\hline 2013 & 26 \\
\hline 2014 & 13 \\
\hline 2015 & 29 \\
\hline & \\
\hline
\end{tabular}

Sumber: Data Investigasi Kecelakaan Kerja PT X Tahun 2012 - 2015.

Berdasarkan tabel di atas, dapat disimpulkan bahwa angka kecelakaan kerja di PT X tidak mengalami penurunan meskipun sudah dilakukan penerapan program PEKA. Oleh karena itu, berdasarkan studi dan permasalahan di atas, perlu dilakukan pengukuran tingkat kematangan BBS di PT X. Tujuan dari penelitian ini adalah untuk menganalisis tingkat kematangan BBS dalam program PEKA di PT $X$.

\section{METODE PENELITIAN}

Penelitian ini merupakan penelitian observasional karena peneliti hanya melakukan observasi tanpa memberikan perlakuan kepada subjek penelitian. Analisis data dalam penelitian ini bersifat deskriptif karena peneliti akan mendeskripsikan hasil penelitian tanpa melakukan uji statistik di dalamnya. Rancangan penelitian yang dilakukan adalah cross sectional karena penelitian ini hanya dilakukan dalam satu kurun waktu tertentu saja (Husein, 2010).

Objek dalam penelitian ini adalah Behavior Based Safety (BBS) yang diimplementasikan dalam program Pengamatan Keselamatan Kerja (PEKA) di PT X. Populasi penelitian adalah seluruh safety officer PT X, yaitu sebanyak 4 orang. Pengambilan sampel akan dilakukan dengan teknik total sampling yaitu teknik pengambilan sampel secara keseluruhan atau mengambil sampel seluruh anggota populasi.

Teknik pengumpulan data dalam penelitian ini adalah dengan menggunakan teknik wawancara untuk menentukan tingkat kematangan BBS. Wawancara akan dilakukan kepada safety officer mengenai setiap acuan pada behavioral safety maturity matrix, yang meliputi (Cooper, 2009): 
1. Ownership

2. Sampling tools

3. Training

4. Observation approach

5. Contact rate

6. Quality of observation

7. Feedback

8. Data use

9. Sustainability reviews

10. Marketing

Lembar wawancara merupakan modifikasi dari lembar wawancara yang disusun oleh Ayu Irlianti (2014) dan disesuaikan dengan behavior safety maturity matrix berdasarkan konsep dari Cooper (2009).

Setiap acuan di atas akan diukur tingkat kematangannya yang dapat dikelompokkan sesuai dengan level pencapaian penerapan BBS yang biasa disebut dengan behavioral safety maturity ladder yang terdiri dari 5 level yaitu Cooper (2009):

1. Beginning (level 1)

2. Developing (level 2)

3. Performing (level 3)

4. High performing (level 4)

5. Excelling (level 5)

\section{HASIL PENELITIAN}

Berikut merupakan tingkat kematangan dari 10 acuan dalam behavioral safety maturity matrix atau matriks kematangan perilaku aman berdasarkan teori Cooper (2009) dalam program PEKA di PT X sesuai dengan hasil wawancara dengan safety officer:

\section{Ownership}

Berdasarkan hasil wawancara dengan safety officer, dapat diketahui bahwa rasa kepemilikan responden selaku pihak manajemen sangat tinggi terhadap program PEKA. Namun, hal ini tidak selaras dengan rasa kepemilikan tenaga kerja terhadap program PEKA, responden menyatakan bahwa rasa kepemilikan tenaga kerja terhadap program PEKA masih sangat rendah, hal ini dibuktikan dengan sedikitnya laporan PEKA yang dilaporkan oleh tenaga kerja. Namun di samping itu, setiap tenaga kerja mempunyai rasa kepedulian yang tinggi terhadap keselamatan, hal ini dibuktikan dengan tingginya angka perilaku aman di PT X. Oleh karena itu, acuan ini berada pada level 2 (developing).

\section{Sampling Tools}

Perilaku yang diobservasi telah didefinisikan oleh pihak manajemen, dalam hal ini adalah pihak HSE PT $X$, namun definisi masih bersifat umum untuk setiap perilaku yang dapat diamati dalam PEKA, belum dilakukan pendefinisian perilaku secara spesifik. Informasi ini berdasar pada hasil wawancara dengan safety officer. Dengan demikian, dalam acuan ini berada pada level 3 (performing).

\section{Training}

Training mengenai PEKA tidak dilaksanakan secara khusus, namun materi tentang PEKA dijadikan sebagai salah satu materi yang selalu disisipkan dalam pemberian training tentang HSE yang diadakan oleh PT X. Sehingga setiap tenaga kerja pasti pernah mendapatkan materi mengenai PEKA yang berisi cara melakukan observasi, cara melaporkan, dan memberikan umpan balik. Berdasarkan pernyataan tersebut, maka dapat disimpulkan bahwa acuan ini berada pada level 3 (performing).

\section{Observation Approach}

Berdasarakan hasil wawancara dengan safety officer, didapat informasi bahwa observasi yang dilakukan dalam program PEKA menggunakan pendekatan observasi manajemen dan antar karyawan. Dengan demikian, acuan ini berada pada level 4 (high performing).

\section{Contact Rate}

Kegiatan observasi dalam program PEKA dapat dilakukan setiap hari oleh tenaga kerja berdasarkan hasil wawancara dengan safety officer. Oleh karena itu, acuan ini berada pada level 4 (high performing).

\section{Quality of Observation}

Berdasarkan hasil wawancara dengan safety officer, kualitas observasi atau pengamatan yang dilaksanakan oleh tenaga kerja lebih berfokus pada keselamatan dan tingkat partisipasi serta observasi. Sehingga acuan ini berada pada level 3 (performing).

\section{Feedback}


Berdasarkan hasil wawancara yang telah dilakukan, seluruh responden dari safety officer menyatakan bahwa umpan balik atau feedback yang seharusnya diberikan oleh observer kepada orang yang diobservasi bersifat dua arah, dimana komunikasi dua arah tersebut bertujuan untuk mengidentifikasi penyebab dan mengambil tindakan korektif sesegera mungkin, meskipun feedback tersebut hanya diberikan dari observer kepada individu yang diobservasi (menggunakan saluran umpan balik). Oleh karena itu, acuan ini berada pada level 3 (performing).

\section{Data Use}

Berdasarkan hasil wawancara dengan safety officer, kegiatan pengamatan atau observasi yang dilakukan dalam proses PEKA dilakukan pencatatan dan dihitung tingkat pemenuhan partisipasinya kemudian dibandingkan dengan kuota yang telah ditargetkan dan juga dilakukan perhitungan persentase pelaporan tiap aspek yang diamati setiap bulan kemudian dilakukan perekapan pelaporan PEKA secara tahunan untuk melihat bagaimana tren pelaporan PEKA tiap tahunnya, sehingga dapat diketahui besar pemenuhan target yang telah ditetapkan.

Selanjutnya, data tersebut akan dijadikan sebagai dasar untuk menentukan arah program K3 yang akan dibuat dengan target akhir yaitu menurunkan angka kecelakaan kerja pada umumnya serta menurunkan angka unsafe action pada khususnya. Dengan demikian, acuan ini berada pada level 4 (high performing).

\section{Sustainability Reviews}

Berdasarkan hasil wawancara dengan safety officer peninjauan program PEKA dilakukan setiap bulan oleh pihak manajemen internal HSE. Jadi tidak ada campur tangan dari pihak luar maupun ahli independen dalam melakukan peninjauan. Sehingga pada acuan ini, tingkat kematangannya berada pada level 3 (performing).

\section{Marketing}

Menurut safety officer, PT X telah melakukan beberapa upaya untuk meningkatkan partisipasi tenaga kerja agar melakukan pelaporan PEKA. Salah satu upaya yang dilakukan adalah memberikan penghargaan dalam bentuk reward berupa souvenir sebagai kepada tenaga kerja yang melakukan pelaporan PEKA terbanyak. Oleh karena itu, upaya ini berada pada level 2 (developing).

Berdasarkan analisis hasil di atas, maka secara ringkas, tingkat kematangan program PEKA di PT $\mathrm{X}$ dapat digambarkan pada tabel di bawah ini:

Tabel 3. Tingkat Kematangan Setiap Acuan pada Behavioral Safety Maturity Matrix Penerapan Program PEKA di PT X

\begin{tabular}{|l|c|c|}
\hline No & Acuan & Tingkat Kematangan \\
\hline 1. & Ownership & Developing (2) \\
\hline 2. & Sampling tools & Performing (3) \\
\hline 3. & Training & Performing (3) \\
\hline 4. & Observation approach & High \\
& Performing (4) \\
\hline 5. & Contact rate & High \\
& Performing (4) \\
\hline 6. & Quality of observation & Performing (3) \\
\hline 7. & Feedback & Performing (3) \\
\hline 8. & Data use & Herforming (4) \\
\hline 9. & Sustainabi- lity reviews & Performing (3) \\
\hline 10. & Marketing & Developing (2) \\
\hline
\end{tabular}


Berdasarkan tabel di atas, maka tingkat kematangan pelaksanaan program PEKA di PT X secara garis besar berada pada level 3 atau "Performing" yang berarti orientasi observasi perilaku oleh manajemen sudah berfokus pada keterlibatan atau partisipasi tenaga kerja terhadap penerapan BBS, dimana tenaga kerja yang satu dengan yang lain saling mengamati atau mengobservasi terkait perilaku yang dilakukan di tempat kerja. Feedback diberikan secara verbal langsung setelah pelaksanaan observasi. Pendokumentasian perilaku sudah dilakukan, namun pendokumentasian belum ditujukan untuk meningkatkan keselamatan. Dan partisipasi tenaga kerja dan observasi menjadi fokus perhatian dari pihak manajemen

\section{PEMBAHASAN}

Berdasarkan hasil penelitian, tingkat kematangan Behavior Based Safety dalam program Pengamatan Keselamatan Kerja (PEKA) di PT X berada pada level 2 (developing), level 3 (performing), dan level 4 (high performing). Hal ini menunjukkan bahwa program PEKA yang merupakan salah satu implementasi BBS tidak memiliki level yang selaras untuk setiap acuannya. Sedangkan berdasar teori Cooper (2009) untuk mencapai tujuan, setiap acuan dari BBS perlu berada pada level yang sama atau selaras.

PT X sebagai salah satu Refinery Unit (RU) dari perusahaan energi nasional yang 100\% kepemilikan sahamnya dimiliki oleh Pemerintah Republik Indonesia seharusnya menyelaraskan levelnya untuk mencapai tujuan perusahaan. Berdasar hasil penelitian, sebagian besar acuan dari behavior safety maturity matrix berada pada level 3 (performing) dan terdapat 2 acuan yang mencapai level 4 (high performing). Sehingga perlu dilakukan penyelarasan pada acuan yang berada pada level 2 (developing) dan level 3 (performing) untuk mencapai level 4 (high performing). Oleh karena itu, perlu dilakukan beberapa modifikasi pada beberapa acuan agar program PEKA meningkat menjadi level 4 (high performing), yaitu:

\section{Ownership}

Berdasarkan hasil penelitian, ownership atau rasa kepemilikan tenaga kerja terhadap program PEKA berada pada level 2 (developing), hal ini menunjukkan bahwa rasa kepemilikan tersebut masih rendah karena penyusunan program PEKA diprakarsai oleh manajemen dan didorong adanya kuota, sehingga tenaga kerja tidak berkomitmen untuk menyediakan waktu khusus untuk melakukan pengamatan dan intervensi.

Tetapi berdasarkan hasil wawancara juga didapat bahwa responden mempunyai rasa kepedulian yang tinggi terhadap aspek keselamatan. Jadi, dapat disimpulkan bahwa meskipun tenaga kerja telah memandang bahwa aspek keselamatan merupakan aspek yang paling utama, tetapi rasa kepedulian tersebut masih belum dibuktikan dengan pelaksanaan pelaporan PEKA. Hal yang seharusnya dilakukan untuk mencapai level 4 (high performing) yaitu program PEKA seharusnya disusun oleh sebagian besar tenaga kerja dengan dukungan kuat dari manajemen sehingga setiap peran mempunyai rasa kepemilikan yang tinggi baik terhadap aspek keselamatan maupun pelaksanaan pelaporan PEKA.

\section{Sampling Tools}

Definisi perilaku yang diobservasi masih bersifat umum dan belum dilakukan pendefinisian perilaku secara spesifik. Hal ini menyebabkan acuan ini berada pada level 3 (performing). Hal yang seharusnya dilakukan adalah melakukan pendefinisian perilaku secara lebih spesifik agar mencapai level 4 (high performing), misalnya membuat buku panduan untuk setiap aspek yang diamati dalam pelaporan PEKA yang di dalamnya berisi definisi secara spesifik aspek yang dapat diamati dan contohcontoh perilaku yang tidak aman apa saja yang dapat dilaporkan oleh observer serta cara melakukan pelaporan PEKA sehingga hal tersebut mudah dimengerti oleh tenaga kerja.

Selain itu, juga lebih baik jika dilaksanakan sosialisasi serta dilakukan praktek langsung di lapangan agar tenaga kerja lebih paham terkait perilaku yang dapat tenaga kerja amati. 


\section{Training}

Pemberian materi tentang PEKA dalam setiap training HSE kurang efektif dilakukan. Hal ini mungkin dikarenakan training yang diberikan tidak dilaksanakan secara kontinyu dan hanya berisi materi mengenai cara mengobservasi dan memberikan umpan balik, sehingga acuan ini berada pada level 3 (performing).

Training tentang BBS seharusnya diberikan kepada setiap tenaga kerja dan berisi materi mengenai cara mengobservasi (tetapkan tekad lalu amati sekekeliling dan catat keadaan yang substandar), memberikan umpan balik (menggunakan komunikasi 2 arah untuk melakukan identifikasi penyebab dan 2 saluran umpan balik), serta cara melatih tenaga kerja lain agar tercipta proses belajar antar tenaga kerja sehingga tercipta pelaksanaan program yang optimal dan mencapai level 4 (high performing).

\section{Quality of Observation}

Berdasarkan hasil wawancara dengan safety officer, kualitas observasi atau pengamatan yang dilaksanakan oleh tenaga kerja hanya terbatas pada peningkatan keselamatan tenaga kerja dan tingkat partisipasi tenaga kerja, tanpa melihat kualitas observasi yang dilakukan oleh observer yang digambarkan dari hasil pelaporannya sehingga acuan ini berada pada level 3 (performing). Cara yang dapat dilakukan oleh pihak manajemen untuk meningkatkan pelaksanaan pogram dan mencapai tujuan adalah kegiatan observasi seharusnya berfokus pada peningkatan kualitas observasi agar mencapai level 4 (high performing).

Peningkatan terhadap kualitas observasi juga akan berdampak pada peningkatan kualitas pelaporan PEKA yang dilakukan oleh observer, dengan bermodalkan pelaporan yang berkualitas tinggi maka akan didapat informasi yang akurat mengenai suatu permasalahan. Sehingga pihak manajemen dapat melakukan peninjauan dengan lebih akurat.

\section{Feedback}

Berdasarkan hasil penelitian, feedback yang diberikan oleh observer kepada orang yang diobservasi berada pada level 3, yaitu menggunakan komunikasi 2 arah untuk mengidentifikasi penyebab (menggunakan 1 saluran umpan balik). Feedback akan lebih baik jika dilakukan sesuai dengan level 4 (high performing) pada behavioral safety maturity matrix yaitu dengan komunikasi 2 arah untuk mengidentifikasi penyebab dan menggunakan dari 2 saluran umpan balik agar terbentuk diskusi partisipasi.

Diskusi partisipasi yang dilakukan oleh tenaga kerja tentunya akan mendorong terjadinya perubahan perilaku pada setiap anggota diskusi. Hal ini dikarenakan diskusi partisipasi dapat memicu partisipasi aktif dari sasaran dan akan menyebabkan pengetahun atau wawasan yang diperoleh lebih mendalam. Hal ini akan membuat perubahan perilaku dengan strategi ini akan bersifat lebih baik daripada penggunaan kekuasaan atau pemberian informasi (Notoadmodjo, 2012).

\section{Sustainability Reviews}

Acuan ini berada pada level 3 (performing), karena peninjauan program PEKA dilakukan oleh pihak manajemen internal HSE. Kegiatan peninjauan dilakukan setiap bulan untuk melihat bagaimana pencapaian pelaporan PEKA serta persentase pelaporan tiap aspek yang diamati. Selain peninjauan tiap bulan yang dilakukan oleh manajemen internal HSE, untuk mencapai level 4 (high performing) hal yang dapat dilakukan adalah mengadakan peninjauan oleh ahli independen setiap tahunnya.

Peninjauan yang dilakukan oleh ahli independen yang berasal dari eksternal perusahaan akan lebih bersifat objektif dan memiliki beberapa manfaat salah satunya adalah dapat memungkinkan identifikasi kelemahan dalam pengendalian yang dilakukan oleh pihak intern yang sebelumnya tidak diketahui, dengan begitu pihak manajemen internal dapat secara tepat waktu melakukan tindakan pengendalian yang sesuai (Tuanakotta, 2013).

\section{Marketing}

Berdasar hasil penelitian, acuan marketing ini berada pada level 2 
(developing), karena pemberian penghargaan dalam bentuk reward berupa souvenir kepada tenaga kerja yang melakukan pelaporan PEKA terbanyak sebagai bentuk pengakuan diri yang dilakukan oleh pihak manajemen. Level 4 (high performing) dapat dicapai apabila pemberian penghargaan bukan hanya sebagai bentuk penghargaan atau pengakuan individu, namun juga digunakan sebagai bahan promosi dan perayaan prestasi secara reguler. Sehingga diharapkan dapat memotivasi seluruh tenaga kerja di PT X untuk melakukan pelaporan PEKA.

Peningkatan level kematangan dapat dicapai oleh PT X jika melaksankan hal-hal yang harus dilaksanakan pada level selanjutnya dengan baik sesuai dengan behavioral safety maturity matrix berdasarkan teori Cooper (2009). Apabila perbaikan terus dilakukan, tidak menutup kemungkinan bahwa setiap acuan pada behavioral safety maturity matrix dapat mencapai level 5 (excelling).

\section{SIMPULAN DAN SARAN}

Tingkat kematangan Behavior Based Safety dalam program Pengamatan Keselamatan Kerja (PEKA) di PT X berada pada level 2 (developing), level 3 (performing), dan level 4 (high performing) yang secara umum berada pada level 3 (performing). Sedangkan untuk mencapai tujuan, setiap acuan dari BBS perlu berada pada level yang sama atau selaras. Oleh karena itu, perlu dilakukan beberapa modifikasi pada beberapa acuan agar program PEKA meningkat pada level selanjutnya.

\section{DAFTAR PUSTAKA}

Cooper. 2009. Behavioral Safety Interventions: A Review of Process Design Factors. Safety Management.

Framework for Success. Indiana: BSMS Inc.
Handayani, Y., 2011. Pengaruh Penerapan Program Behavior Based Safety Terhadap Penurunan Jumlah Kecelakaan Kerja Di PT Denso Indonesia, Skripsi Fakultas Kesehatan Masyarakat Universitas Pembangunan Nasional Veteran. Jakarta.

Husein, U 2010. Riset Pemasaran dan Bisnis. Jakarta: Gramedia Pustaka Utama.

Irlianti, A. 2014. Evaluasi Penerapan Behavior Based Safety (BBS) Menggunakan Behavioral Safety Maturity Matrix dan DO IT Process (Studi di Lapindo Brantas, Inc), Skripsi. Fakultas Kesehatan Masyarakat Universitas Airlangga. Surabaya.

Ismail, et.al, 2012. Behaviour Based Approach for Quality and Safety Environment Improvement: Malaysian Experience in the Oil and Gas Industry. Procedia Manufacturing. Vol. 35, page: 586594.

Jasiulewicz, et.al. 2015. Behavior Based Intervention for Occupational Safety Case Study. Procedia Manufacturing. Vol. 3, page: 48764883.

Kementerian Kesehatan Republik Indonesia/Data

Kecelakaan.http://www.depkes.go.i d. [Diakses pada 5 November 2015].

National Safety Council., 2011. Injury Facts, 2011 Edition. Itasca, IL: Author.

Notoatmodjo. 2012. Promosi Kesehatan dan Perilaku Kesehatan. Jakarta : Rineka Cipta.

Tuanakotta, T. M. 2013. Audit Berbasis ISA (International Standards on Auditing). Jakarta: Salemba Empat. 